\title{
Editorial 24/3: Electronic Markets and general research
}

\author{
Rainer Alt • Hans-Dieter Zimmermann
}

Published online: 9 August 2014

(C) Institute of Information Management, University of St. Gallen 2014

Dear readers of Electronic Markets,

We are happy to present you the third issue of volume 24 which includes five papers that were submitted to the general research section of Electronic Markets. As described in the editorial section of the last issue (Alt and Österle 2014a, b) general research papers are a key element of the research paper section and currently account for slightly more than half of all submissions (as per end 2013). With a similar acceptance rate to special issue papers (approx. $11 \%$ ), it is not surprising that Electronic Markets also sees two general research issues within one volume. After the first issue in 2014, the current third issue represents the second in volume 24 . We wish to use this opportunity to describe the variety of topics relevant to Electronic Markets (EM 2014) in more detail.

In the first place, the spectrum of topics is related to the development of electronic commerce itself. When the journal was launched back in 1991, electronic markets were limited to exchanging a high volume of electronic business documents between application systems (EDI), to proprietary electronic exchanges in the financial sector, computerized reservation systems in the airline industry as well as to videotex-based early electronic shopping systems. Although electronic markets were attributed a significant potential (Malone et al. 1987, Österle and Schmid 2008), the performance and diffusion of key technologies were still in their infancy. In particular, the Internet since the late 1980s has pushed electronic commerce and electronic markets towards a broader area range of applications. From the retrospective various stages of development

\footnotetext{
R. Alt $(\triangle)$

Information Systems Institute, University of Leipzig,

Grimmaische Str. 12, 04109 Leipzig, Germany

e-mail: rainer.alt@uni-leipzig.de

H.-D. Zimmermann

FHS St. Gallen, University of Applied Sciences, Rosenbergstrasse 59, 9001 St. Gallen, Switzerland

e-mail: hansdieter.zimmermann@fhsg.ch
}

may be observed which not only spurred a wealth of (business and technological) innovations, but also contributed additional research topics and questions. For example, in their compelling review of research on electronic commerce since 1988, Clarke and Pucihar (2013) have repeatedly indicated that the topics of Electronic Markets evolved in tandem with those published at the Bled eCommerce Conference. They identified three phases of evolution: the EDI era between 1988 and 1995, the eBusiness era between 1996 and 2004, and the eInteraction era since 2005. Others described the evolution in five stages (e.g. Tassabehji (2003) based on Earl (2000)) or more informal in multiple periods (e.g. Turban et al. 2006).

Table 1 builds on the existing models and presents an updated view on the evolution phases and emphasizes that electronic markets have actually penetrated all aspects of modern economies. In the beginning proprietary technologies and solutions existed that were limited to specific application areas and primarily large organizations. The Internet was a key enabler in the early e-commerce era since it provided access to information independent of the underlying technological platform and interconnectivity across various providers. Static presences on the Internet appeared, but soon became more interactive and dynamic in the early e-business era. During this period many new businesses as well as exceeded expectations on the role of electronic markets emerged. However, the burst of the e-commerce bubble in the early 2000s showed that electronic commerce did not become obsolete, but shed light on linking the early e-business developments with the entire business operations and the subsequent potential to shape digital value chains. Following this idea a variety of important technologies spread, in particular, mobile devices, social media and virtualization technologies. The early digital ecosystems showed that electronic markets are now at the heart of business models in many industries (e.g. Alt and Klein 2011, 45) and with more convergence on the way they will contribute to the transformation of entire industries. For example, digital ecosystems providers, 
Table 1 Six stages in the development of Electronic Markets' topics

\begin{tabular}{|c|c|}
\hline Stage of evolution & Examples of key topics \\
\hline Proprietary era (1970-1990) & $\begin{array}{l}\text { - Communication of documents (EDI) via proprietary communication } \\
\text { networks (videotex, X.25-based value added networks) } \\
\text { - Definition of electronic standards for transactions (e.g. ANSI, EDIFACT, } \\
\text { Tradacoms) and directories (e.g. X.500) } \\
\text { - Focused electronic markets and interorganizational information systems } \\
\text { (e.g. airline reservation systems, financial exchanges, electronic shopping) }\end{array}$ \\
\hline Early E-Commerce (1990-1995) & $\begin{array}{l}\text { - Basic Internet technologies (e.g. TCP/IP, HTML, XML) are used for } \\
\text { static HTML pages and web-based EDI } \\
\text { - Emerging standard application for intraorganizational processes (ERP) } \\
\text { and business process orientation } \\
\text { - Internet-based electronic malls pave the way for multi-vendor platforms } \\
\text { which offer joint functionalities (e.g. directories, payment) }\end{array}$ \\
\hline Early E-Business (1995-2000) & $\begin{array}{l}\text { - Complex dynamic database-based web presences with more integration } \\
\text { with business processes and application systems for online sales etc. } \\
\text { - Evolution of XML-based standards for electronic business (e.g. cXML } \\
\text { and eClass for electronic catalogs) } \\
\text { - Evolution of standard application systems for E-Business (e.g. electronic } \\
\text { catalogs, supply chain and customer relationship management) }\end{array}$ \\
\hline Early digital value chains (2000-2005) & $\begin{array}{l}\text { - Emphasis of E-Commerce shifted from B2C to B2B as well as to B2E } \\
\text { (Business-to-Employee) } \\
\text { - Integration of electronic business technologies with enterprise applications } \\
\text { and emergence of integration solutions (e.g. portals, EAI) } \\
\text { - Mobile channel becoming available based on GSM and RFID technologies }\end{array}$ \\
\hline Early digital ecosystems (2005-2010) & $\begin{array}{l}\text { - Ecosystems with multi-channel clients linked with centralized electronic (market) } \\
\text { platforms (e.g. App stores, open source communities) } \\
\text { - Social media as enhancement and/or platforms for E-Business } \\
\text { (e.g. Social CRM, Social Shopping) } \\
\text { - On-premise solutions are becoming available as shared SaaS and } \\
\text { cloud-based solutions }\end{array}$ \\
\hline Early convergence (2010 -) & $\begin{array}{l}\text { - Omni-channel environments where information is shared among all } \\
\text { user locations (e.g. mobile, web, office/shop, car, public transport) } \\
\text { - Consumerization shifts control to end user and user-centered life solutions } \\
\text { (e.g. for health, mobility, finance) are becoming available } \\
\text { - Leverage technologies for storing and analyzing large volumes of data } \\
\text { (big data) for business scenarios }\end{array}$ \\
\hline
\end{tabular}

such as Apple and Google, are increasingly collaborating with traditional actors in the health, mobility or financial sector.

The six stages in the evolution of electronic markets illustrate the broad nature of the electronic market phenomenon primarily from a functional point of view. In fact, the achievements in a certain stage have not necessarily substituted each other, but each phase itself has brought innovations that have proven valuable for subsequent developments. For example, the definitions of electronic documents in the EDI era are still valuable, though supported by modern technologies. The phases not only show the pace of innovation since the advent of electronic commerce, but also that each phase has given birth to a variety of new firms and players as well as that the barriers among industries and markets have often changed and became more blurred. In summary, electronic markets, refer to all "forms of networked business where multiple suppliers and customers interact for economic purposes within one or among multiple tiers in economic value chains. As a broad concept, there are many forms of electronic markets:
- In a narrow sense, electronic markets are mainly conceived as allocation platforms with dynamic price discovery mechanisms involving atomistic relationships. Popular examples originate from the financial (e.g., CBOT, XETRA) and energy markets (e.g., EEX, ICE).

- In a broader sense, price discovery is not critical for electronic markets. These solutions emphasize longer term relationships and processes for enabling business transactions (e.g., electronic procurement solutions) and/or knowledge management (e.g. product development, problem and incident management)" (EM 2014).

The journal Electronic Markets seeks submissions on both interpretations of electronic markets. This means that the ITbased support of market structures and relationships also comprises all kinds of IT-enabled distributed processes between businesses as well as consumers. Potential authors are encouraged to ensure that their research addresses a (see Table 2): 
Table 2 Scope of general research in Electronic Markets

\begin{tabular}{ll}
\hline Scope & Examples \\
\hline Topics & $\begin{array}{l}\text { E-Commerce \& E-Business, supply chain \& customer } \\
\text { relationship management, EDI, standards, market } \\
\text { mechanisms and services }\end{array}$ \\
Problem & $\begin{array}{l}\text { Application-driven (e.g. specific to industries, such } \\
\text { as automotive, banking, logistics, retailing) and } \\
\text { embedded in theoretical concepts }\end{array}$ \\
Discipline & $\begin{array}{l}\text { Use of methodologies from computer science, economics, } \\
\text { engineering, management, psychology, sociology to } \\
\text { electronic markets' research }\end{array}$ \\
Methodology & $\begin{array}{l}\text { Concepts and theories, action/consortial/design research, } \\
\text { empirical hypothesis testing, single/multiple case } \\
\text { studies }\end{array}$ \\
\hline
\end{tabular}

- Topic that is relevant to Electronic Markets, i.e. submissions need to have a link to a certain aspect of IT-enabled networked business.

- Problem that may be described as applied in nature. Although theoretical papers are possible in Electronic Markets, the authors should at least pinpoint practical implications.

- Discipline which is suitable for answering the research question. Following the broad understanding of electronic markets, research methods may come from various disciplines.

- Methodology that is sufficiently described, applied appropriately, and linked to a detailed discussion of findings as well as novel and insightful conclusions.

If you require information on the scope of Electronic Markets, the Editorial Office is always open for your questions. We also hope that you will find all of the described aspects in the following five papers of the current volume. In the first article "Satisfaction with virtual communities in B2B financial services: social dynamics, content and technology" the authors Evangelos Chompis, Roger W. H. Bons, Bart van den Hooff, Frans Feldberg, and Hans Horn explore satisfaction with virtual communities in a financial services setting. The authors identify the main determinants of member satisfaction of a Business-to-Business (B2B) virtual community among financial service professionals. They hypothesize that three sources of value drive user satisfaction in a B2B virtual community and propose a respective theoretical model. The model is tested via a Partial Least Square Analysis on data gathered in a survey among participants in a leading financial service community. The research findings extend the virtual community research from the Business-to-Consumer into the B2B domain and contribute to the growing body of knowledge on Social Media, especially in the relatively unexplored domain of $\mathrm{B} 2 \mathrm{~B}$.
The second article is titled "ICT supported healthy lifestyle interventions: design lessons" and co-authored by Luuk P. A. Simons, J. Felix Hampe, and Nick A. Guldemond. It addresses the main question of "how to motivate participants to large health behavior improvements?" by adopting a design research approach. The authors conducted two design and test iterations to add ICT support to traditional face-to-face coach formats: web-based eDashboarding and integrating mobile smart phone apps (mApps) in the coach relationship. Based on both iterations several design lessons were extracted. The study suggests three basic requirements that need to be addressed when designing ICT-supported healthy lifestyle interventions: heath effectiveness, coaching performance, and ICT value adding.

The article "Perceived risks and risk management of social media in an organizational context" authored by Juha Munnukka and Pentti Järvi addresses the current issue of how perceived risks prevent businesses from utilizing social media in their marketing communication. The research explores the key types of risks that organizations associate with using social media in marketing. Furthermore, the authors also explore the effectiveness of procedural control and proactive focusing processes in managing these risks. The study is based on 174 structured interviews which were carried out among Finnish business organizations. The results indicate that business organizations perceive three types of risk related to the use of social media: time-loss, financial, and functional. In addition, the results indicate that companies applied procedural control mechanisms to manage time-loss risks. An organization's familiarity with social media was found to have a strong effect on time-loss as well as on other types of risks.

The paper "Attitude contagion in consumer opinion platforms: posters and lurkers" by Boris Bartikowski and Gianfranco Walsh shows how product reviews published by consumers on opinion platforms affect the buying behavior of other consumers. Posters on the one hand are defined as consumers who regularly post content while consumers who primarily read content on community platforms are referred to as lurkers on the other. To better understand the motivation of posters and lurkers to use a community platform, an online survey was conducted among users of two French consumer opinion platforms. In the empirical model these user types moderate the relationship between a novel variable "perceived community attitude towards a product" and product- and brand attitudes. The results reveal interesting implications for businesses that monitor the opinions on their products and services. For example, different recommendations are derived from the research findings depending on whether positive or negative reviews prevail on the platforms.

Another paper in the context of online shopping communities investigates the role of offering personalization 
functionalities, such as recommendations, self-customization or social login and other personalized services. Based on a survey among 600 online customers in Greece the authors Ilias O. Pappas, Panos E. Kourouthanassis, Michail N. Giannakos and Vassilios Chrissikopoulos, analyze the relationship between personalization, positive and negative emotions and the intention to purchase. As the title "Shiny happy people buying: the role of emotions on personalized e-shopping" indicates, achieving positive emotions is of foremost importance for electronic shopping community providers. While the research confirms that negative emotions also have negative implications on the intention to purchase, it reveals that "no evidence of relationship between personalization and negative emotions" (Pappas et al. 2014) exists. This means that understanding the link between personalization functionalities, emotions and the intention to purchase promises to reap "low hanging fruit" for online retailers.

Please note that the latter two papers are available via Springer's open access option and are freely available via SpringerLink. We hope that you make use of this possibility and enjoy reading the current issue of Electronic Markets.

Best regards from Leipzig and St. Gallen,

Rainer Alt, Hans-Dieter Zimmermann

\section{References}

Alt, R., \& Klein, S. (2011). Twenty years of electronic markets researchlooking backwards towards the future. Electronic Markets, 21(1), $41-51$.

Alt, R., \& Österle, H. (2014a). Electronic Markets and practice-orientation. Electronic Markets, 24(1), 1-4.

Alt, R., \& Österle, H. (2014b). Electronic Markets and journal sections. Electronic Markets, 24(2), 77-79.

Clarke, R., \& Pucihar, A. (2013). Electronic Interaction Research 19882012 through the lens of the Bled eConference. Electronic Markets, 23(4), 271-283.

Earl, M. J. (2000). Evolving the E-Business. Business Strategy Review, 11(2), 33-38.

EM, Scope, Website of Electronic Markets (EM) journal (2014). http:// www.electronicmarkets.org/about-em/scope/.

Malone, T. W., Yates J., \& Benjamin, R. I. (1987). Electronic markets and electronic hierarchies. Communications of the ACM, 30(6), 484-497.

Österle, H., \& Schmid, B. (2008). Quo Vadis Electronic Markets? Electronic Markets, 18(3), 206-210.

Pappas, I. O., Kourouthanassis, P. E., Giannakos, M. N., \& Chrissikopoulos, V. (2014). Shiny happy people buying: the role of emotions on personalized e-shopping. Electronic Markets, 24(3). doi:10.1007/s12525-014-0153-y.

Tassabehji, R. (2003). Applying E-commerce in business. London: Sage.

Turban, E., King, D., Viehland, D., \& Lee, J. (2006). Electronic Commerce 2006 - a managerial perspective. Upper Saddle River: Pearson Prentice Hall. 